\author{
Department of Chemistry \\ University of Southern California \\ University Park \\ Los Angeles, California, 90089-1661
}

\title{
DISCLAIMER
}

\begin{abstract}
This report was prepared as an account of work sponsored by an agency of the United States Government. Neither the United States Government nor any agency thereof, nor any of their employees, makes any warranty, express or implied. or assumes any legal liability or responsibility for the accuracy, completeness, or usefulness of any information, apparatus, product, or process disclosed, or represents that its use would not infringe privately owned rights. Refer. ence herein to any specific commercial product, process, or service by trade name, trademark, manufacturer, or otherwise does not necessarily constitute or imply its endorsement, recommendation, or favoring by the United States Government or any agency thereof. The views and opinions of authors expressed herein do not necessarily state or reflect those of the United States Government or any agency thereof.
\end{abstract}


Table of Contents

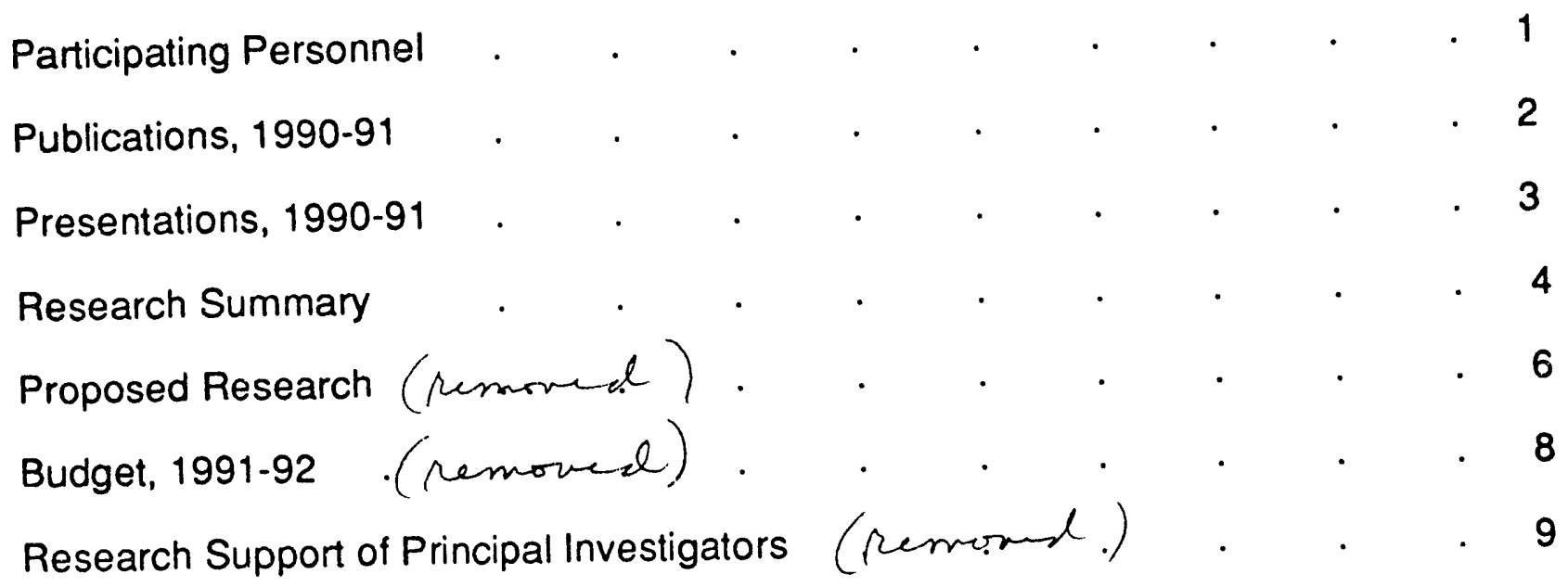

i 
DOE - Office of Basic Energy Sciences

Participating Personnel

"Synthesis of Novel Associating Water-Soluble Copolymers"

Personnel

Faculty: Thieo E. Hogen-Esch, Principal Investigator, Professor of Chemistry, Department of Chemistry, University of Southern California, Los Angeles, California, 90089-1661.

Eric. J. Amis, Associate Professor of Chemistry, Department of Chemistry, University of Southern California, Los Angeles, California, 90089-1661.

Dr. Y-X. Zhang, Institute of Organic Chemistry, Academia Sinica, Shanghai, People's Republic of China.

Studentsa: Frank Hwang, Graduate Student.

Thomas Seery, Graduate Student.

Maryam Yassini, Graduate Student.

Xiaoyi Xie, Graduate Student.

a. At the Department of Chemistry, University of Southern California (USC), Los Angeles. 


\section{Synthesis of Novel Associating Water-Soluble Copolymers}

\section{DOE, Office of Basic Energy Sciences}

\section{List of Publications}

1. Y-X. Zhang, A-H. Da, G. B Butler and T.E. Hogen-Esch, J. Polym. Sci. (Chem. Ed.), 31 ( ), 000, 1991.

2. Y-X. Zhang, A-H. Da, Y-C. Chen, G.B. Butler and T.E. Hogen-Esch, J. Macromol. Sci., A 27 (5), 593 (1990).

3. T.E. Hogen-Esch, M. Yassini, Y-X. Zhang, F. Hwang, E.J. Amis and T.A.P. Seery, Polym. Preprts., 31 (2), 460 (1990).

4. Y-X. Zhang, A-H. Da, T.E. Hogen-Esch and G.B. Butler, Chapter 10, ACS Symposium Series No.467, "Water Soluble Polymers", pages $159-174$, S. Shalaby, C.L. McCormick and G.B. Butler, Editors.

5. S. Gopal Krishnan, G.B. Butler, T.E. HogenEsch and N-Z. Zhang, Chapter 11, ACS Symposium Series, No. 467, pages 175-188, "Water-Soluble Polymers", S. Shalaby, C.L. McCormick and G.B. Butler, Editors.

6. F. Hwang and T.E. Hogen-Esch, Polym. Preprts., 32 (1), 581 (1991).

7. T.A.P. Seery, M. Yassini, T.E. Hogen-Esch and E.J. Amis, Macromolecules, Submitted.

8. E.J. Amis and T.A.P. Seery, Polymer Preprts, 32 (2), 000 (1991).

9. T.A.P. Seery, J.A. Shorter and E.J. Amis, Polymer, 30, 1197-1203 (1989).

10. D.F. Hodgson and E.J. Amis, invited chapter in Polyelectrolytes: Science and Technologies, M. Hara, Ed., Marcel-Dekker, New York, N.Y. 1991, in press.
A Fluorine Containing Hydrophobically Associating Polymer Synthesis and Solution Properties of Copolymers of Acrylamide and Fluorine Containing Acrylates and Methacrylates.

Synthesis and Solution Properties of Water-Soluble Sulfonated CelluloseBased Polymers and Their Polyacrylamide Graft Copolymers.

Synthesis and Characterization of Fluorocarbon Containing Polyacryamides.

New Fluorocarbon Containing Hydrophobically Associating Polyacrylamide Copolymers.

Hydrophobically Associating lonic Copolymers of Methyldiallyl-1,1-dihydropentadecafluorooctoxyethylammonium Chloride.

Fluorocarbon Modified Water-Soluble Cellulose Derivatives.

Static and Dynamic Light Scattering Characterization of Solutions of Hydrophobically Associating FluorocarbonContaining Polymers.

Static and Dynamic Light Scattering Characterization of Hydrophobically Associating Polymers.

Concurrent Static and Dynamic Light Scattering from Macromolecular Solutions. I. Model Systems in the Low q Regime.

Polyelectrolyte Dynamics. 


\section{Synthesis of Novel Associating Water-Soluble Polymers \\ Presentations (1990-1991)}

F. Hwang and I.E. Hogen-Esch, April 1991, Spring ACS Meeting, Atlanta, Georgia.

T. E. Hogen-Esch, M. Yassini, Y-X. Zhang, F. Hwang, E.J. Amis and T. Seery, August 1990 Washington ACS Meeting.

Y-X. Zhang, A-H. Da, T.E. Hogen-Esch and G.B. Butler, Thirty-third IUPAC International Symposium on Macromolecules, July 8-13, 1990, Montreal, Canada.

Y-X. Zhang, M. Yassini, F. Hwang and I.E. Hogen-Esch, Dupont de Nemours, Wilmington, Delaware, July 15, 1991.

Y-X. Zhang, M. Yassini, F. Hwang and I.E. Hogen-Esch, Aqualon-Hercules, Wilmington, Delaware, August 8, 1991.

$M$. Yassini, Y-X. Zhang and T.E. Hogen-Esch, Temple University, July 16, 1991.

T.E. Hogen-Esch, Iristitut for Wool Research, Aachen, Germany, May 15, 1991.

E.J. Amis, Gordon Research Conference, Polymer Physics, Rhode Island, 1990.

E.J. Amis, Tethered Chains I: International Symposium on the Science of Polymer Surfactants, Minneapolis and Brainerd, $M N$ 1991.

I.A.P. Seeny and E.J. Amis, APS National Meeting, High Polymer Physics Division, Cincinnati, ÖH, 1991.
Fluorocarbon-Modified Water-Soluble Cellulose Derivatives.

Synthesis and Characterization of Fluorocarbon Containing Polyacrylamides.

Water-Soluble Graft Copolymers of 2,3Dihydroxypropylcellulose With Acrylamide and Sodium-2-acrylamido2-methylpropanesulfonate.

A Fluorine-Containing Hydrophobically Associating Polymer.

Fluorocarbon-Containing Water-Soluble Polymers.

Fluorocarbon-Containing Polyacrylamides.

Hydrophobic Association of Fluorocarbon Containing Water-Soluble Copolymers".

Light Scattering and Viscosity of Associating Polymers in Solution.

Structure and Dynamics of Hydrophobically Associating Polymer Solutions.

Light Scattering and Viscosity of Associating Polymers in Solution. 


\section{Research Summary}

- Fluorine-19 NMR studies were undertaken in order to determine the content of fluorine-containing comonomer in a series of acrylamide copolymers. The results indicated that comonomer conversion is essentially quantitative.

- Addition of water-soluble $\left(\mathrm{HOCH}_{2} \mathrm{CH}_{2} \mathrm{SH}\right)$ and water-insoluble $\left(\mathrm{C}_{12} \mathrm{H}_{25} \mathrm{SH}\right)$ radical scavengers indicates that the water-soluble scavenger is effective in reducing molecular weight. The water-insoluble scavenger essentially has no effect. This appears to indicate that the polymerization occurs exclusively in the aqueous phase (see also "Proposed Research").

- We have found that in certain instances, addition of as little as 1 percent salt causes huge increases ( $\sim 20$ fold) in low shear Brookfield viscosity. In other systems, the increases in viscosity are much smaller. It appears that in the former systems viscosities are lower to start with than in the latter systems. This would indicate that addition of salts may lead to strongly enhanced hydrophobic association. The reason for these interesting differences between various solutions is under investigation (see "Proposed Research").

- Perfluorocarbon containing hydroxyethylcellulose (HEC) derivatives were prepared with the structures:

$\mathrm{CelOCH}_{2} \mathrm{CH}_{2} \mathrm{OCH}_{2} \mathrm{CH}(\mathrm{OH}) \mathrm{CH}_{2}$ and $\mathrm{CelOCH}_{2} \mathrm{CH}_{2} \mathrm{OR}$
a) $\mathrm{R}=\mathrm{CH}_{3}\left(\mathrm{CH}_{2}\right)_{7}^{-}$or
b) $\mathrm{CF}_{3}\left(\mathrm{CF}_{2}\right)_{2} \mathrm{CH}_{2}-$ or
c) $\mathrm{CF}_{3}\left(\mathrm{CF}_{2}\right)_{6} \mathrm{CH}_{2}{ }^{-}$ 
Surprisingly, derivatives $\mathbf{1 b}, \mathbf{2 b}$ and $\mathbf{2 c}$ were wholly or partially insoluble.

Derivatives $1 \mathrm{a}$ and $\mathbf{1 c}$ are effective viscosifying polymers for which the Brookfield viscosity vs degree of substitution profile goes through a maximum. Derivative $1 c$ is substantially more effective compared with 1a consistent with the stronger hydrophobic character of the perfluoroalkyl groups.

- $\quad \operatorname{Poly}(\mathrm{N}, \mathrm{N}$-dimethylacrylamide) (4 samples) and Poly(N-acryl-N-methylpiperazine) (10 samples) were prepared by anionic polymerization in THF at -780 in the presence of Cs or coordinated Li counter cations. Molecular weights (SEC) range from 3800 250,000 . The polymers are soluble in methanol, $\mathrm{H}_{2} \mathrm{O}$ and chloroform and to a lesser extent, in THF and $\mathrm{CH}_{2} \mathrm{Cl}_{2}$. Molecular weight distributions were found to be fairly monodisperse $(1.11<\mathrm{D}<2.69)$. (See "Proposed Research").

- Static and dynamic light scattering experiments performed on solutions of hydrophobically associating polyacrylamide copolymers illuminate the underlying molecular basis for the previous observations. Aggregation effects for these polymers are observed at polymer concentrations as low as $10 \mathrm{ppm}$. These effects are manifest by large radii of multichain aggregates as well as small radii attributed to collapsed chains. The aggregates are, apparently, denser structures than random coils; comparable to microgels observed by others. With the addition of a potassium perfluorooctyl carboxylate surfactant, single chains are observed which exhibit less dense structures reflecting random coil configurations. A previously unreported temperature and concentration dependent slow relaxation mode which is independent of scattering vector was observed. 

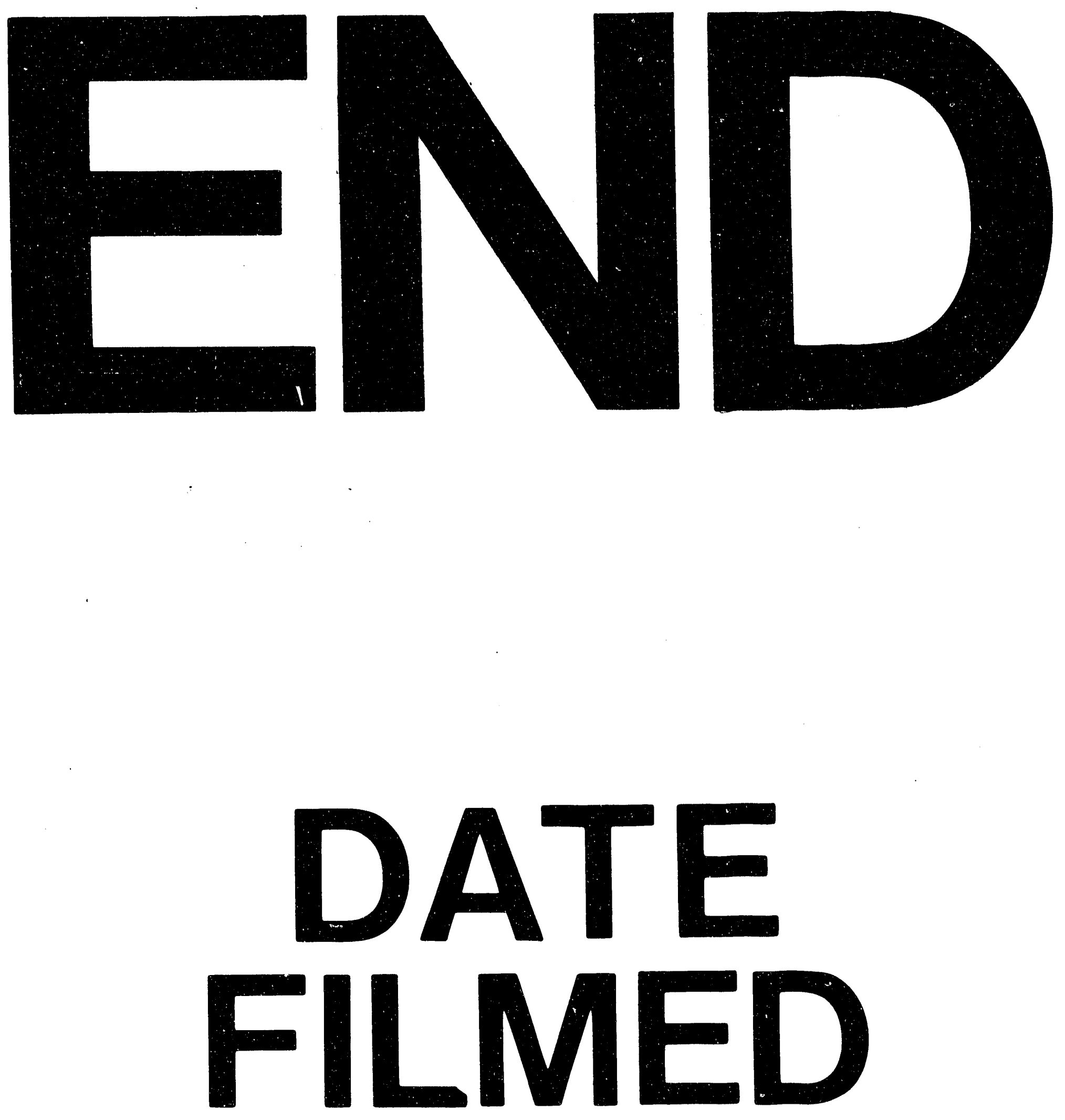

1

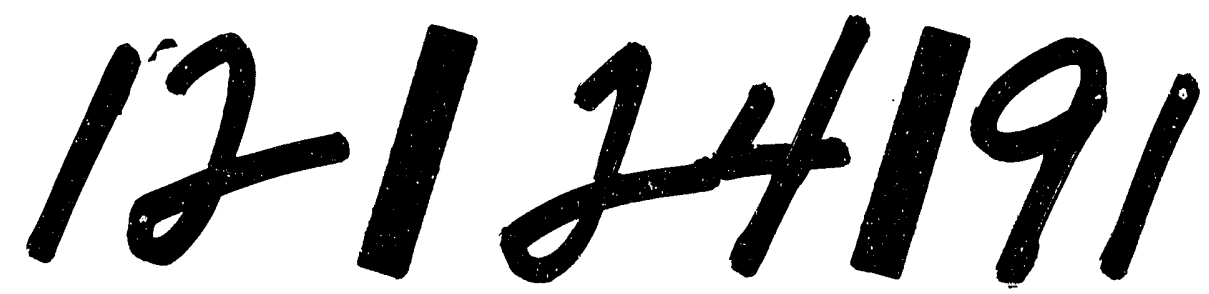


